\title{
Groundwater flow to the coastal ocean
}

Ann E. Mulligan and Matthew A. Charette

\section{Introduction}

Water flowing through the terrestrial landscape ultimately delivers fresh water and dissolved solutes to the coastal ocean. Because surface water inputs (e.g., rivers and streams) are easily seen and are typically large point sources to the coast, they have been well-studied and their contributions to ocean geochemical budgets are fairly well known. Similarly, the hydrodynamics and geochemical importance of surface estuaries are well known. Only recently has significant attention turned toward the role of groundwater inputs to the ocean. Historically, such inputs were considered insignificant because groundwater flow is so much slower than riverine flow. Recent work however has shown that groundwater flow through coastal sediments and subsequent discharge to the coastal ocean can have a significant impact on geochemical cycling and it is therefore a process that must be better understood.

Groundwater discharge into the coastal ocean generally occurs as a slow diffuse flow but can be found as large point sources in certain terrain, such as karst. In addition to typically low flow rates, groundwater discharge is temporally and spatially variable, complicating efforts to characterize site-specific flow regimes. Nonetheless, the importance of submarine groundwater discharge (SGD) as a source of dissolved solids to coastal waters has become increasingly recognized, with recent studies suggesting that SGD- derived chemical loading may rival surface water inputs in many coastal areas (Moore, 1996; Bugna et al., 1996; Kim et al., 2003). So while the volume of water discharged as SGD may be small relative to surface discharge, the input of dissolved solids from SGD can surpass that of surface water inputs. For example, SGD often represents a major source of nutrients in estuaries and embayments (Krest et al., 2000; Charette et al., 2001). Excess nitrogen loading can result in eutrophication and its associated secondary effects including decreased oxygen content, fish kills, and shifts in the dominant flora (Valiela et al., 1992; Slomp and Van Cappellen, 2004).

First, let us define "groundwater" in a coastal context. We use the term to refer to any water that resides in the pore spaces of sediments at the land-ocean boundary. Hence, such water can be fresh terrestrially-derived water that originates as rainwater infiltrating through the subsurface or it can represent saline oceanic water that flows through the sediments (Fig. 1). Therefore, groundwater discharging to coastal waters can have salinity that spans a large range, 
being some mixture of the two endmembers. We therefore use the terms fresh SGD and saline SGD to distinguish these sources of fluid and brackish SGD to mean a mixture of the fresh and saline endmembers.

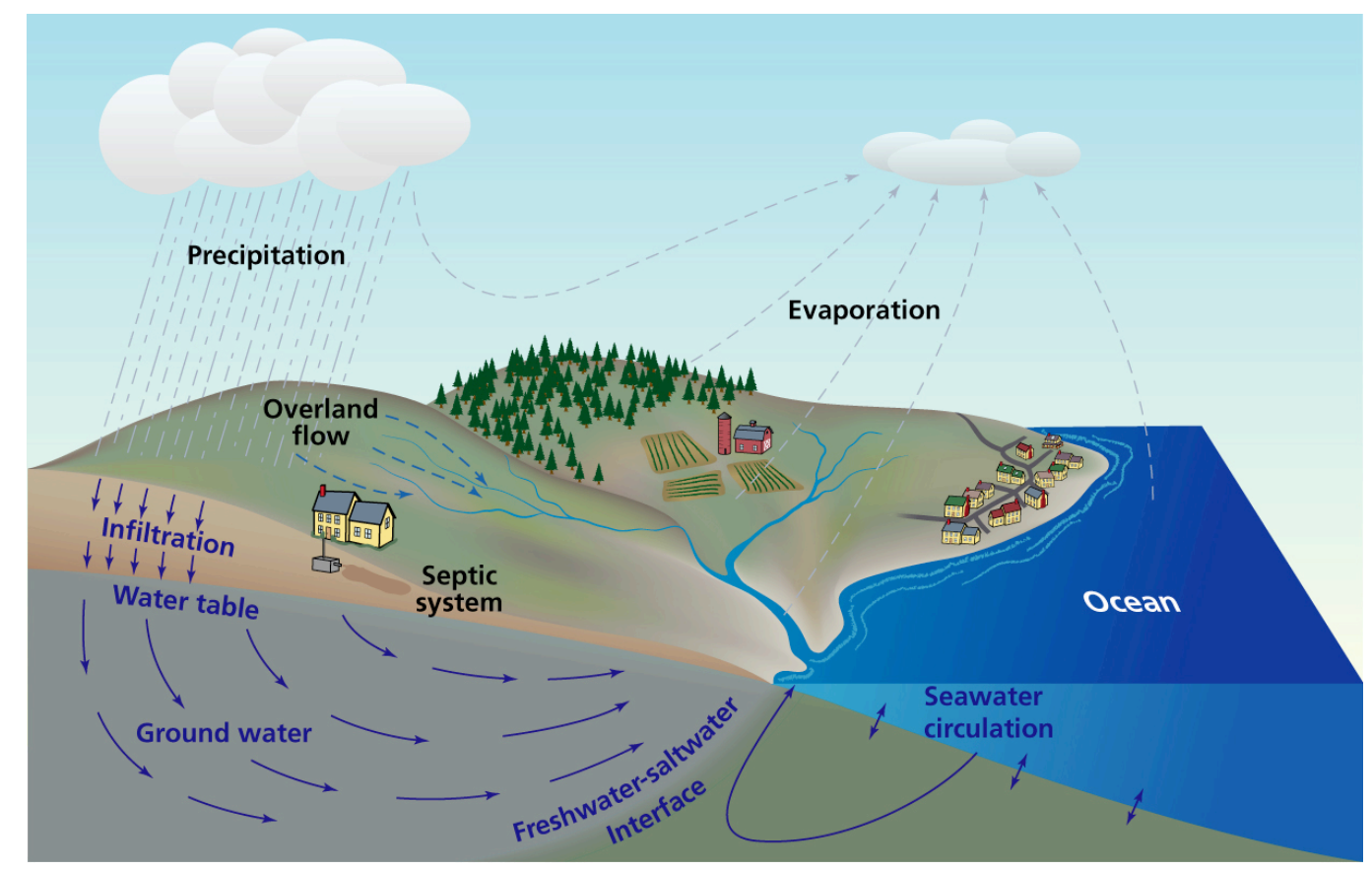

Figure 1: Simplified water cycle at the coastal margin. (Modified from Heath, 1998).

\section{Basics of Groundwater Flow}

Groundwater flow in the subsurface is driven by differences in energy - water flows from high energy areas to low energy. The energy content of a unit volume of water is determined by the sum of gravitational potential energy, pressure energy, and kinetic energy:

$$
\text { energy per unit volume }=\rho g z+P+\frac{\rho V^{2}}{2}
$$

where $\rho$ is fluid density, $g$ is gravitational acceleration, $z$ is elevation of the measuring point relative to a datum, $P$ is fluid pressure at the measurement point, and $V$ is fluid velocity. Because groundwater flows very slowly (on the order of $1 \mathrm{~m} / \mathrm{d}$ or less), its kinetic energy is very small relative to its gravitational potential and pressure energies and the kinetic energy term is therefore ignored. By removing the kinetic energy term and rearranging eqn. (1) to express energy in terms of mechanical energy per unit weight, the concept of hydraulic head is developed: 


$$
\text { energy per unit weight }=\text { hydraulic head }=z+\frac{P}{\rho g}
$$

Groundwater therefore flows from regions of high hydraulic head to areas of low hydraulic head.

Because groundwater flows through a porous media, the rate of flow depends on soil properties such as the degree to which pore spaces are interconnected. The property of interest in groundwater flow is the permeability, $\mathbf{k}$, which is a measure of the ease with which a fluid flows through the soil matrix. Groundwater flow rate can then be calculated using Darcy's law, which says that the flow rate is linearly proportional to the hydraulic gradient:

$$
\mathbf{q}=-\frac{\rho \mathbf{g k}}{\mu}(\nabla h)
$$

where $\mathbf{q}$ is the darcy flux, or flow rate per unit surface area, and $\mu$ is fluid viscosity. A more general expression of Darcy's law is:

$$
\mathbf{q}=-\frac{\mathbf{k}}{\mu}(\nabla P+\rho \mathbf{g} \nabla z)
$$

In inland aquifers, the density of groundwater is constant and eqn. (4) is reduced to the simpler form of Darcy's law (eqn. 3). In coastal aquifers, however, the presence of saline water along the coast means that the assumption of constant density is not valid and so the more inclusive form of Darcy's Law, eqn. (4), is required.

\section{Groundwater flow at the coast}

Several forces drive groundwater flow through coastal aquifers, leading to a complex flow regime with significant variability in space and time (Fig. 2). The primary driving force of fresh submarine groundwater discharge is the hydraulic gradient from the upland region of a watershed to the surface water discharge location at the coast. Freshwater flux is also influenced by several other forces at the coastal boundary that also drive seawater through the sediments. For example, seawater circulates through a coastal aquifer under the force of gravity (Li et al., 1999; Li and Jiao, 2003), from oceanic forces such as waves and tides (Taniguchi et al., 2002; Burnett et al., 2003), as a result of dispersive circulation along the freshwater-saltwater boundary within the aquifer (Kohout, 1960), and from changes in upland recharge (Michael et al., 2005). Several other forcing mechanisms exist, but they are generally only present in specific settings. For example, tidal height differences across many islands can drive flow through the subsurface (Chanton et al, 2003). All of these forcing mechanisms affect the rate of fluid flow for both fresh 
and saline groundwater and are ultimately important in controlling the submarine discharge of both fluids.

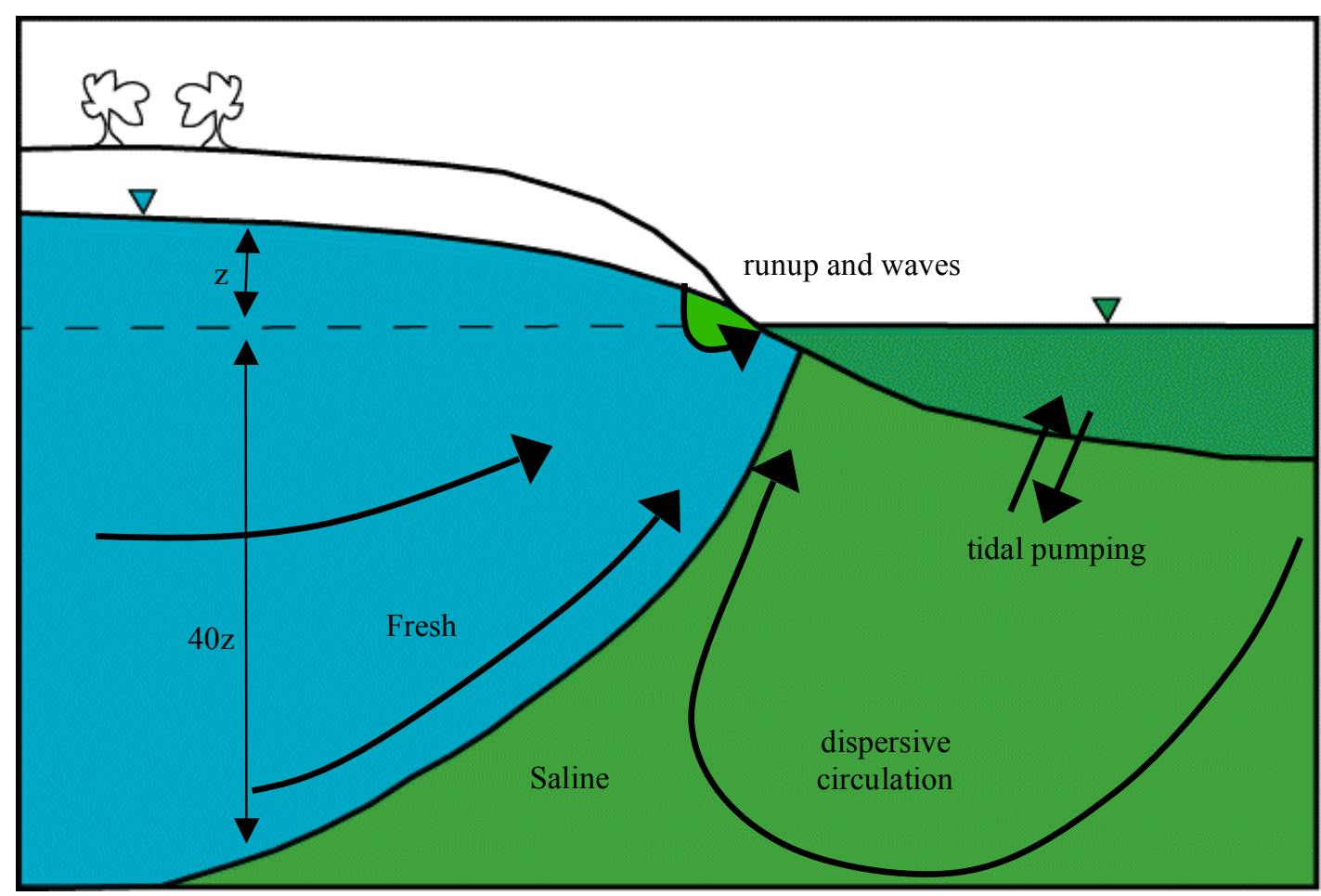

Figure 2: Simplification of an unconfined coastal groundwater system. Water flow is driven by the inland hydraulic gradient, tides, beach runup and waves, and dispersive circulation. Other forcing mechanisms can drive fluid through coastal sediments, including seasonal changes in recharge to the inland groundwater system (Michael et al., 2005) and tidal differences across islands (Chanton et al., 2003).

The analysis of coastal groundwater flow must account for the presence of both fresh and saline water components. When appropriate, such as in regional scale analysis or for coarse estimation purposes, an assumption can be made that there is a sharp transition, or interface, between the fresh and saline groundwater. While this assumption is not strictly true, it is often appropriate and invoking it results in simplifying the analysis. For example, we can estimate the position of the freshwater-saltwater interface by assuming a sharp interface, no flow within the saltwater region, and only horizontal flow within the fresh groundwater. Invoking these assumptions means that the pressures at adjacent points along the interface on both the 
freshwater and saltwater sides are equal. Equating these pressures and rearranging, the depth to the interface can be calculated as follows:

$$
\text { interface depth }=\frac{\rho_{1}}{\rho_{2}-\rho_{1}} * z=40 z
$$

where $\rho_{1}$ is the density of fresh water $\left(1000 \mathrm{~kg} / \mathrm{m}^{3}\right)$ and $\rho_{2}$ is the density of seawater $(1025$ $\mathrm{kg} / \mathrm{m}^{3}$ ). This equation states that the depth of the interface is 40 times the elevation of the water table relative to mean sea level. While eqn. (5) is only an approximation of the interface location, it is very helpful in thinking about freshwater and saltwater movement in response to changes in fresh groundwater levels. As recharge to an aquifer increases, water levels increase and the interface is pushed downward. This is also equivalent to pushing the interface seaward and the net effect is to force saltwater out of the subsurface and to replace it with fresh water (Michael et al., 2005). The opposite flows occur during times of little to no recharge.

While the sharp-interface approach is useful for conceptualizing flow at the coast, particularly in large-scale problems, the reality is more complex. Not only does the saline groundwater flow, but a zone of intermediate salinity extends between the fresh and saline endmembers, establishing what many refer to as a "subterranean estuary" (Moore, 1999). Like their surface water counterparts, these zones are hotbeds of chemical reactions. Because the water in the interface zone ultimately discharges into coastal waters, the flow and chemical dynamics within the zone are critically important to understand. Research into these issues has only just begun.

\section{Detecting and Quantifying SGD}

As a first step in quantifying chemical loads to coastal waters, the amount of water flowing out of the subsurface must be determined. This is a particularly difficult challenge because groundwater flow is spatially and temporally variable. A number of qualitative and quantitative techniques have been developed to sample submarine groundwater discharge, with each method sampling a particular spatial and temporal scale. Because of limitations with each sampling method, several techniques should be used at any particular site. 


\section{Physical approaches}

Infrared thermography

Infrared imaging has been used to identify the location and spatial variability of SGD by exploiting the temperature difference between surface water and groundwater at certain times of the year (Portnoy et al., 1998; Miller and Ullman, 2004; Mulligan and Charette, 2006). While this technique is quite useful for identifying spatial discharge patterns, it has not yet been applied to estimating flow rates.

An example of thermal infrared imagery is shown in Figure 3, an image of the head of Waquoit Bay, a small semi-enclosed estuary on Cape Cod, Massachusetts, USA. In late summer, the groundwater temperature is approximately $13^{\circ} \mathrm{C}$ whereas surface water is about 710 degrees warmer. Locations of SGD can be seen in the infrared image as locations along the beach face with cooler temperature than the surrounding surface water. The image clearly shows spatial variability in SGD along the beach face, information that is extremely valuable in designing an appropriate field sampling campaign (e.g., Mulligan and Charette, 2006). 


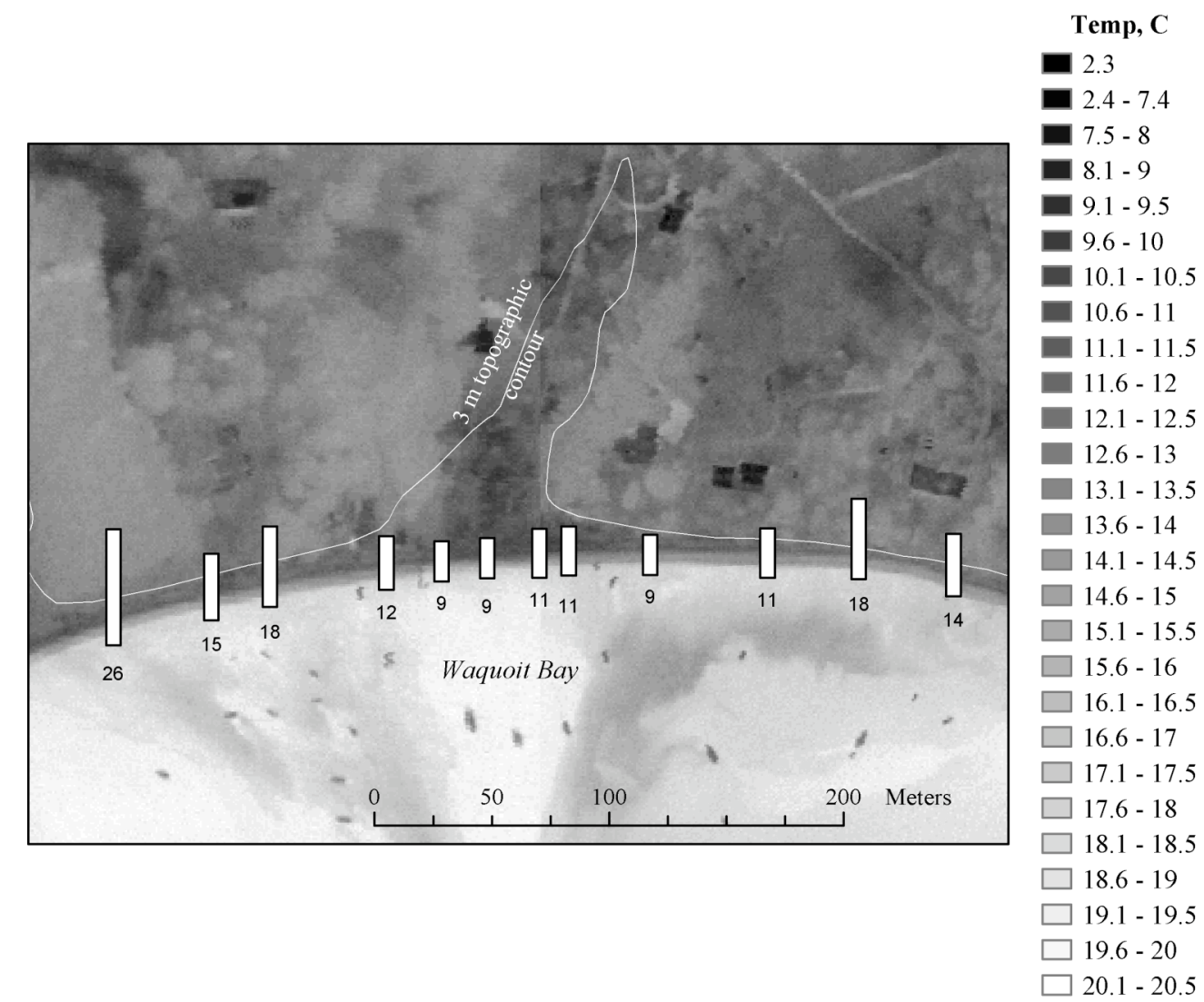

Figure 3: Thermal infrared image of the head of Waquoit Bay, Massachusetts. Light grays imply higher temperatures and darker shades show lower temperatures. Lower temperatures within the bay indicate regions influenced by submarine groundwater discharge. The bars show average groundwater seepage rates as measured by manual seep meters from high tide to low tide. Numbers below the bars are average rates in $\mathrm{cm} \mathrm{d}^{-1}$. Modified from Mulligan and Charette (2006).

\section{Hydrologic approaches}

There are two hydrologic approaches to estimating SGD: the mass balance method and Darcy's law calculation. Both methods are typically applied to estimating fresh groundwater discharge, although Darcy's law can be used to estimate saline flow into and out of the seafloor.

To apply Darcy's Law, one must measure the soil permeability and hydraulic head at several locations (at least two) at the field site. Data must also be gathered to determine the cross-sectional flow area. The field data are then used with Darcy's law to calculate a groundwater flow rate into the coastal ocean. The main disadvantages of this approach include the fact that permeability is highly heterogeneous, often ranging over several orders of magnitude, and so an "average" value to use with Darcy's law is seldom, if ever, well known. 
Furthermore, hydraulic head measurements require invasive, typically expensive, well installations. Finally, hydraulic head is a point measurement and capturing the spatial variability therefore requires installing many wells. The primary advantage of this approach is that it is well established and easy to implement: head measurements are easy to collect once wells are installed and the flux calculations are simple.

The mass balance approach to estimating SGD requires ascertaining all inputs and outputs of water flow, except SGD, through the groundwatershed. Assuming a steady-state condition over a specified time frame, the groundwater discharge rate is calculated as the difference between all inputs and all outputs. Implementing this approach can be quite simple or can result in complex field campaigns, but the quality of the data obviously affect the level of uncertainty. Even with extensive field sampling, water budgets are seldom known with certainty and so should be used with that in mind. Furthermore, if the spatial and temporal variability of SGD is needed for a particular study, the mass balance approach is not appropriate.

\section{Direct measurements: Seepage meters}

Submarine groundwater discharge can be measured directly with seepage meters. Manual seepage meters (Fig. 4) are constructed using the tops of 55-gallon drums, where one end is open and placed into the sediment. The top of the seepage meter has a valve through which water can flow; a plastic bag pre-filled with a known volume of water is attached to the valve so that inflow to or outflow from the sediments can be determined. After a set length of time, the bag is removed and the volume of water in the bag is measured. The change in water volume over the sampling period is then used to determine the average flow rate of fluid across the water-sediment boundary over the length of the sampling period. These meters are very simple to operate, but they are manually intensive and are sensitive to wave disturbance and currents (Shinn et al., 2002). Furthermore, they only sample a small flow area and so many meters are needed to characterize the spatial variability seen at most sites (Fig. 3). 


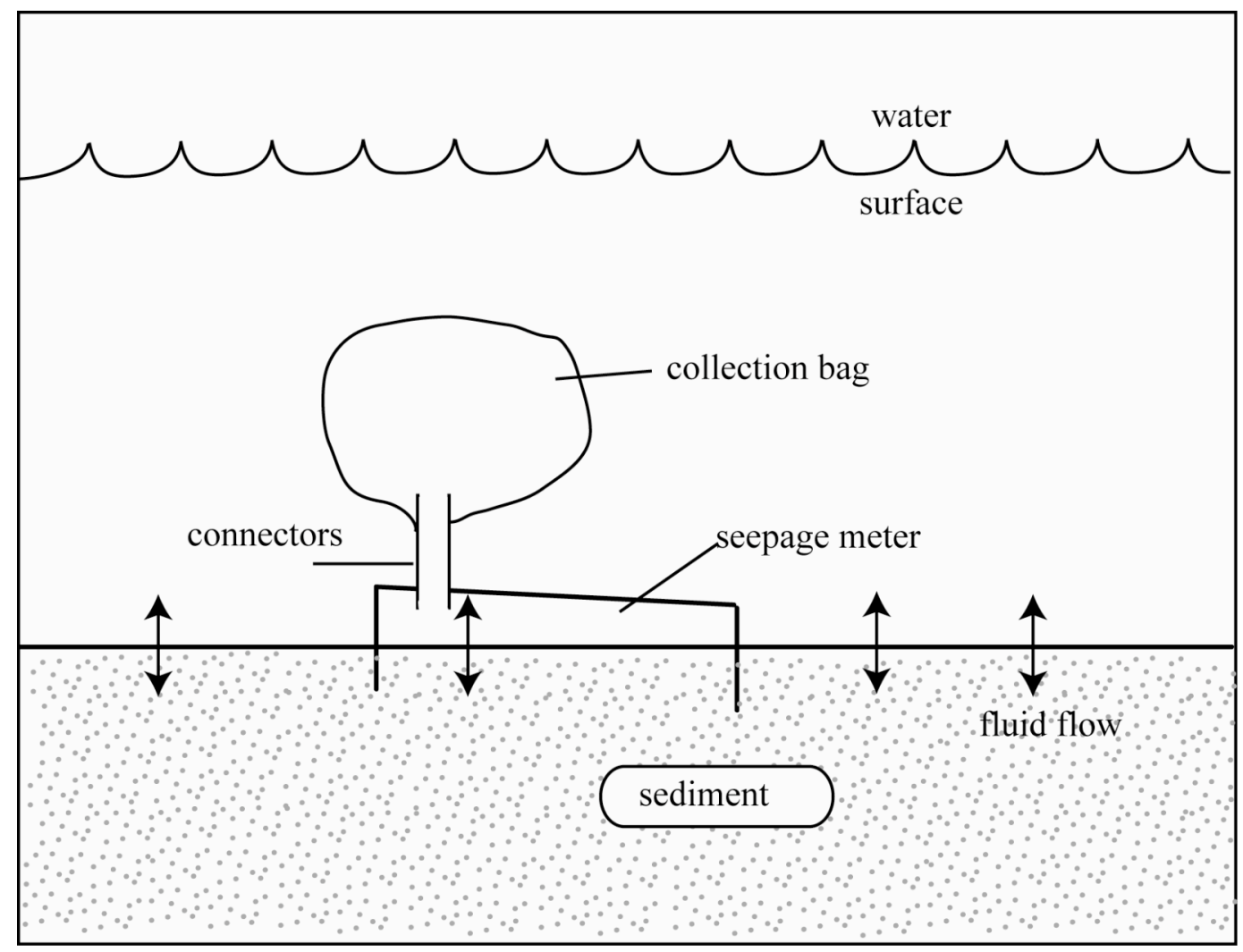

Figure 4: Graphic of a manual seepage meter deployed at the sediment-water interface. These meters can be constructed using the top of a 55-gallon drum. The collection bag serves as a fluid reservoir so that both inflow to and outflow from the sediments can be measured. Modified from Lee (1977).

Recently, several other technologies have been applied toward developing automated seep meters. Technologies include the heat-pulse method (Taniguchi and Fukuo, 1993), continuous heat (Taniguchi and Iwakawa, 2001), ultrasonic (Paulson et al., 2001), and dyedilution (Sholkovitz et al., 2003). These meters can be left in place for days and often weeks and will measure seepage without the manual intervention needed using traditional seepage meters. The trade-off with these meters is that they are expensive and therefore only a limited number are typically employed at any given time. An example of seepage measurements made using the dye-dilution meter is shown in Fig. 5. Note that the seepage rates are inversely proportional to tidal height. As the tide rises, the hydraulic gradient from land to sea is reduced, seepage slows, and the flow reverses indicating that seawater is flowing into the aquifer at this location during high tide. Conversely, at low tide, the hydraulic gradient is at its steepest and SGD increases. 


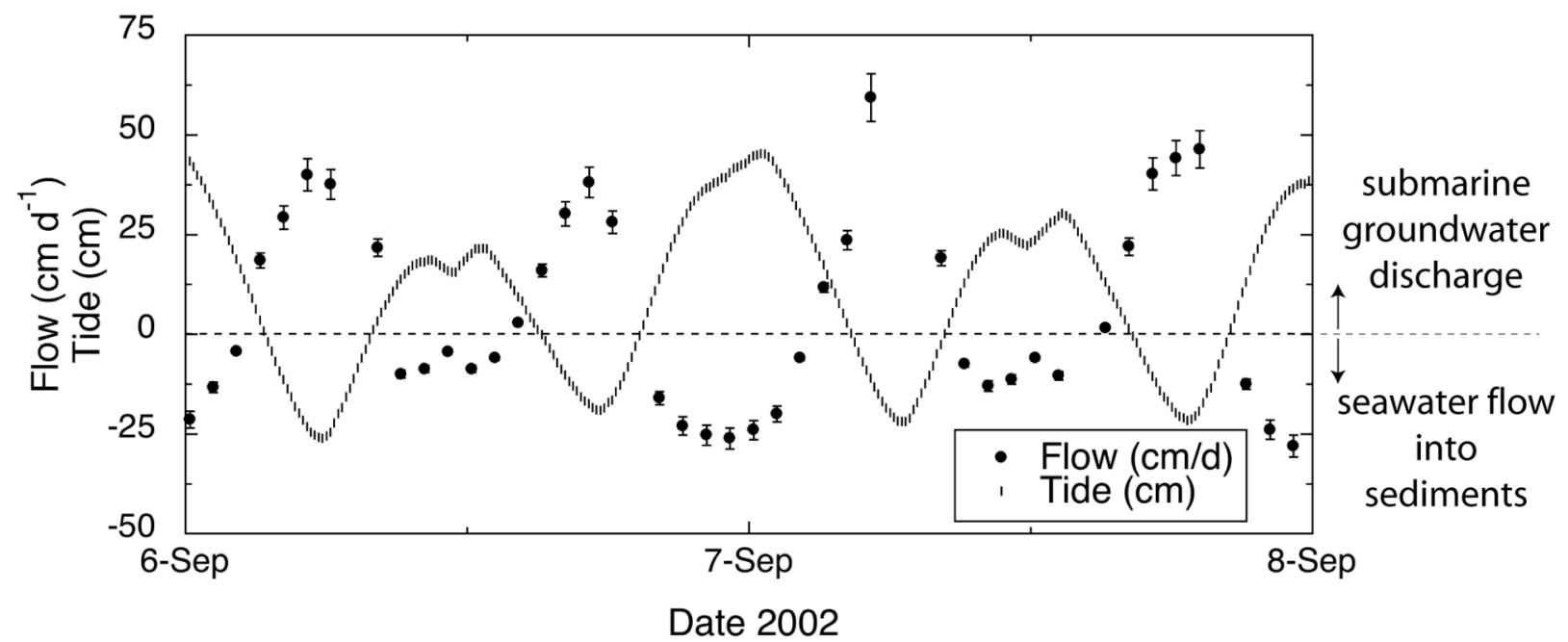

Figure 5: Seepage rates at Waquoit Bay, Massachusetts, USA, measured using a dyedilution automated seepage meter. (Modified from Sholkovitz et al., 2003).

\section{Chemical tracers}

The chemical tracer approach to quantifying SGD has an advantage over seepage meters in that it provides an integrated flux over a wide range of spatial scales from estuaries (e.g. Charette et al., 2001) to continental shelves (e.g. Moore, 1996). The principle of using a chemical tracer is simple: find an element or isotope that is highly enriched (or depleted) in groundwater relative to other sources of water, like rivers or rainfall, to the system under study. If SGD is occurring, then the flux of this element via groundwater will lead to enrichment in the coastal zone that is well above background levels in the open ocean (Fig. 6). A simple mass balance/box model for the system under study can be performed, where all sources of the tracer other than groundwater are subtracted from the total inventory of the chemical. The residual inventory, or "excess", is then divided by the concentration of the tracer in the discharging groundwater to calculate the groundwater flow rate.

Naturally occurring radionuclides such as radium isotopes and radon-222 have gained popularity as tracers of SGD due to their enrichment in groundwater relative to other sources and their built in radioactive "clocks" (Burnett et al., 2006). The enrichment of these tracers is owed to the fact that the water-sediment ratio in aquifers is usually quite small and that aquifer 
sediments (and sediments in general) are enriched in many $\mathrm{U}$ - and Th-series isotopes; while many of these isotopes are particle reactive and remain bound to the sediments, some like Ra can easily partition into the aqueous phase (Webster et al., 1995). Radon-222 $\left(\mathrm{t}_{1 / 2}=3.82 \mathrm{~d}\right.$ ) is the daughter product of ${ }^{226} \mathrm{Ra}\left(\mathrm{t}_{1 / 2}=1600 \mathrm{y}\right)$ and a noble gas, therefore it is even more enriched in groundwater than radium.

A key issue when comparing different techniques for measuring SGD is the need to define the fluid composition that each method is measuring (i.e., fresh, saline, or brackish SGD). For example, whereas hydrogeological techniques are estimates of fresh SGD, the radium and radon methods include a component of recirculated seawater. Therefore, it is often not possible to directly compare the utility of these techniques. Instead, they should be regarded as complementary (see, for example, Mulligan and Charette, 2006).

Moore (1996) was the first to demonstrate that SGD could impact chemical budgets on the scale of an entire coastline. Using literature estimates of residence time, riverine discharge/suspended sediment load, and the activity of desorbable ${ }^{226} \mathrm{Ra}$ on riverine particles, Moore determined that only $\sim 50 \%$ of the ${ }^{226} \mathrm{Ra}$ inventory on the inner continental shelf off North and South Carolina, USA, could be explained by surface inputs (Fig. 6). The remaining inventory enters the system via SGD. Using an estimate of groundwater ${ }^{226} \mathrm{Ra}$, it is estimated that the groundwater flux to this region of the coastline is on the order of $40 \%$ of the river water flux (Moore, 1996).

The approach for quantifying SGD using ${ }^{222} \mathrm{Rn}$ is similar to that for radium $\left({ }^{226} \mathrm{Ra}\right)$, except for a few key differences: (1) ${ }^{222} \mathrm{Rn}$ loss to the atmosphere must be accounted for in many situations, (2) there is no significant source from particles in rivers, and (3) decay must be accounted for owing to its relatively short half-life. Working in the northeastern Gulf of Mexico, Cable et al. (1996) provided the first example of ${ }^{222} \mathrm{Rn}$ use to quantify SGD to the coastal zone. The strong pycnocline that develops in the summer time allowed the authors to look at fluid flow from the sediments into the bottom boundary layer without having to correct for the air-sea loss of ${ }^{222} \mathrm{Rn}$. Using this approach, they estimated that diffuse SGD in a $620 \mathrm{~km}^{2}$ area of the inner shelf was equivalent to $\sim 20$ first magnitude springs. 


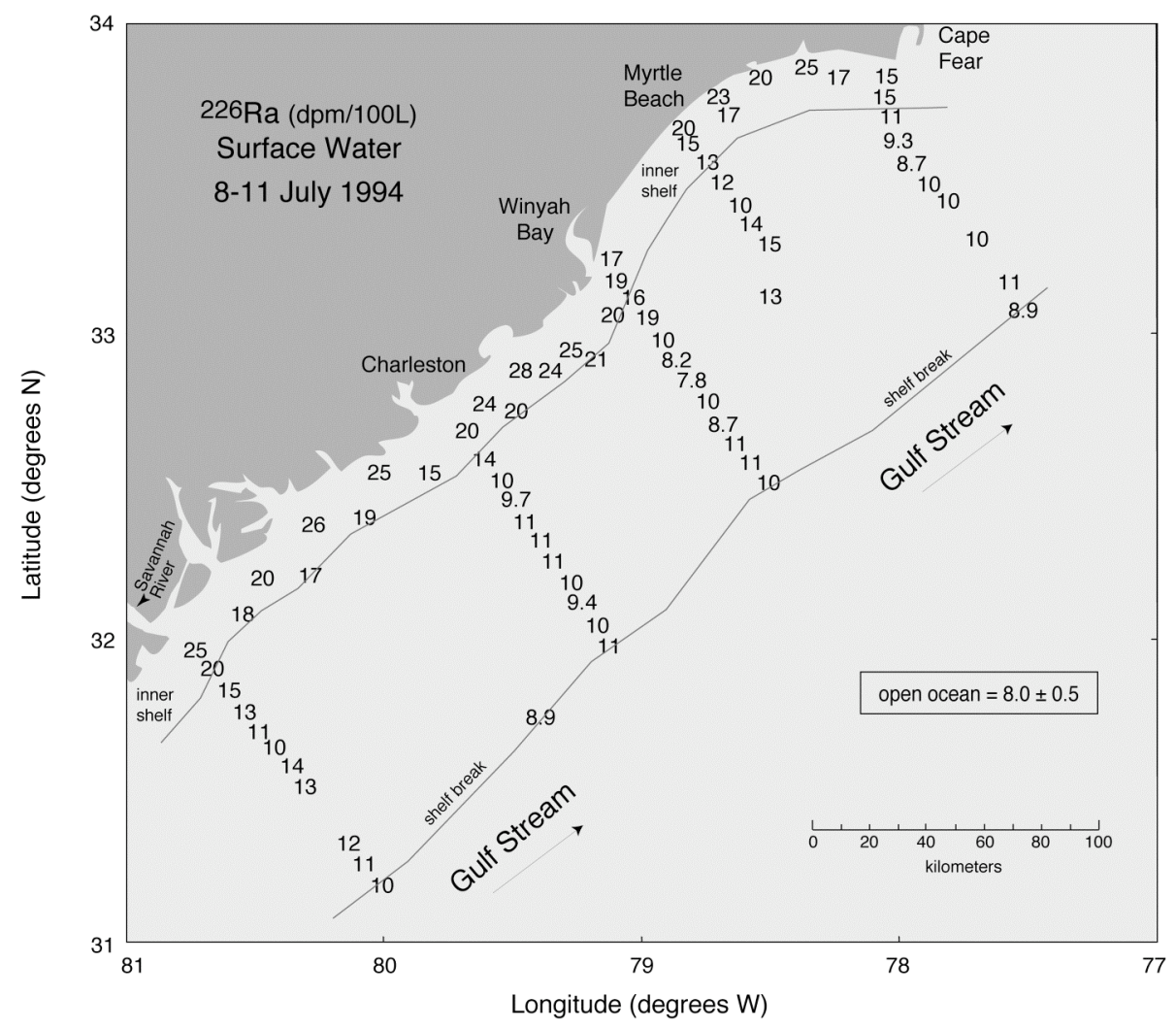

Figure 6. The distribution of ${ }^{226} \mathrm{Ra}$ offshore South Carolina revealed high activities on the inner shelf that decreased offshore. Moore (1996) used the excess ${ }^{226} \mathrm{Ra}$ to estimate regional SGD fluxes.

Since 2000, a number of SGD estimation technique intercomparison experiments have been conducted through a project sponsored by the Scientific Committee on Oceanic Research (SCOR) and the Land-Ocean Interaction in the Coastal Zone (LOICZ) Project (Burnett et al., 2006). During these intercomparisons, several methods (chemical tracers, different types of seep meters, hydrogeologic approaches, etc.) were run side-by-side to evaluate their relative strengths and weaknesses. Figure 7 displays a comparison from the Shelter Island, NY experiment of calculated radon fluxes (based on measurements from a continuous radon monitor) with seepage rates measured directly via the dye-dilution seepage meter. During the period (May 17-20) when both devices were operating at the same time, there is a clear and reproducible pattern of higher radon and water fluxes during the low tides. There is also a suggestion that the seepage spikes 
slightly led the radon fluxes, which is consistent with the notion that the groundwater seepage is the source of the radon (the radon monitor was located offshore of the seepage meter). The excellent agreement in patterns and overlapping calculated advection rates (seepage meter $=2-37$ $\mathrm{cm} \mathrm{day}^{-1}$, average $=12 \pm 8 \mathrm{~cm} \mathrm{day}^{-1} ;$ radon model $=0-34 \mathrm{~cm} \mathrm{day}^{-1}$, average $=11 \pm 7 \mathrm{~cm} \mathrm{day}^{-1}$ ) by these two completely independent assessment tools is reassuring.

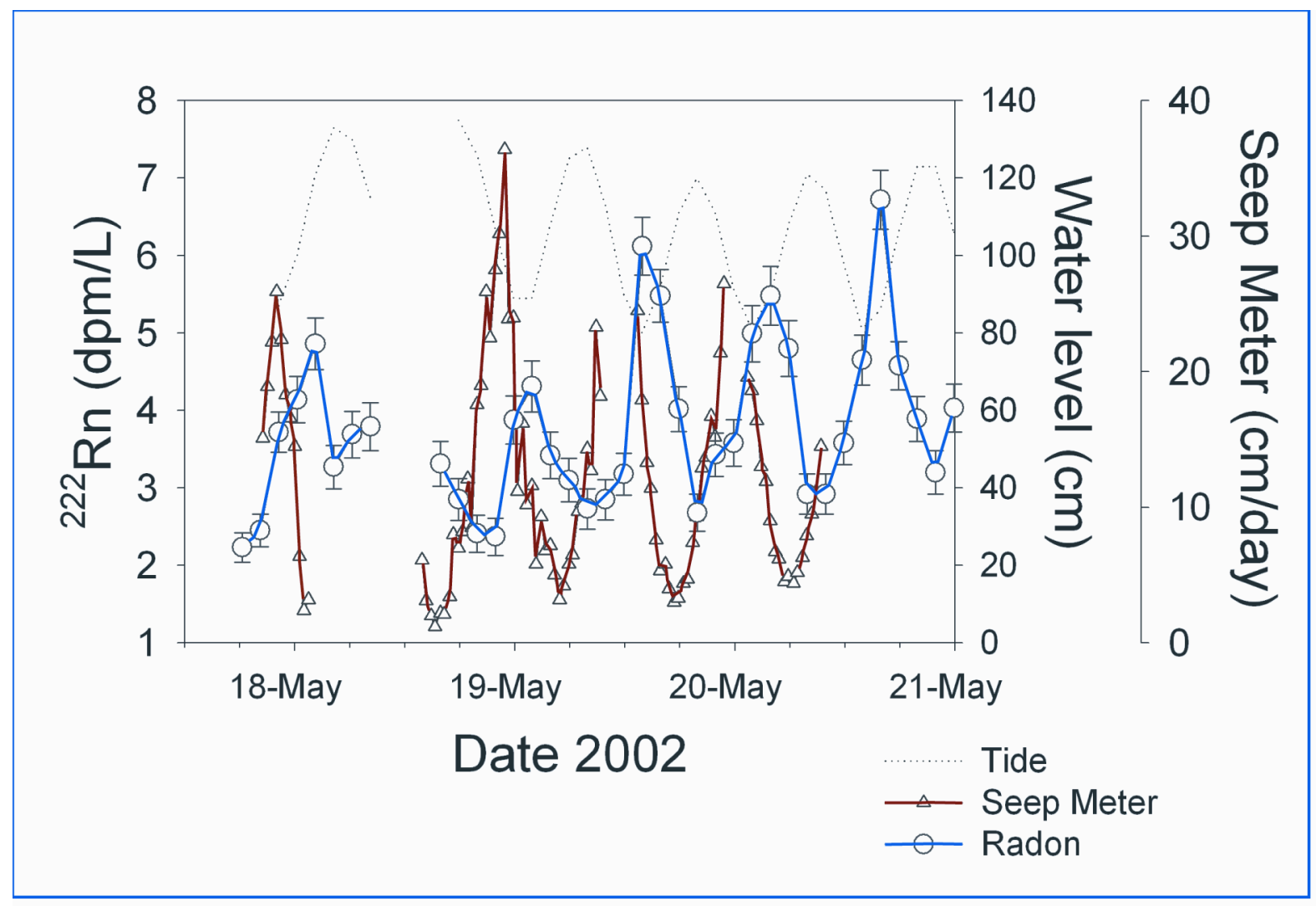

Figure 7. Plot comparing variations in SGD at Shelter Island, NY between an automated seepage meter and the continuous radon method.

\section{Geochemistry of the Subterranean Estuary}

The magnitude of chemical fluxes carried by SGD is influenced by biogeochemical processes occurring in the subterranean estuary, defined as the mixing zone between groundwater and seawater in a coastal aquifer (Moore, 1999). The reactions in such underground 
estuaries are presumed to be similar to the surface estuary (river water/seawater) counterpart, though few comprehensive studies of chemical cycling in subterranean estuaries have been undertaken. Drivers of biogeochemical reactions in these environments include oxidationreduction gradients, desorption-sorption processes and microbially-driven diagenesis.

In a study of the Waquoit Bay subterranean estuary, Charette and Sholkovitz (2002) reported on a large accumulation of iron (hydr)oxides at the fresh-saline interface. These iron oxide rich sands could act as a geochemical barrier by retaining and accumulating certain dissolved chemical species carried to the subterranean estuary by groundwater and/or coastal seawater. Significant accumulation of phosphorus in the iron oxide zones of the Waquoit cores exemplifies this process (Fig. 8).

Phosphorous is not the only nutrient that can be retained/removed via reactions in the subterranean estuary. The microbial reduction of nitrate to inert dinitrogen gas, a process known as denitrification, is known to occur in the redox gradients associated with fresh and saline groundwater mixing (e.g. Talbot et al., 2003). Conversely, ammonium, which is more soluble in saline environments, may be released within the subterranean estuary's mixing zone. While the overall importance of SGD on the global cycle of certain chemical species remains to be seen (Charette and Sholkovitz, 2006), there is little doubt that SGD is important at the local scale both within the United States and throughout the world. 
(a)
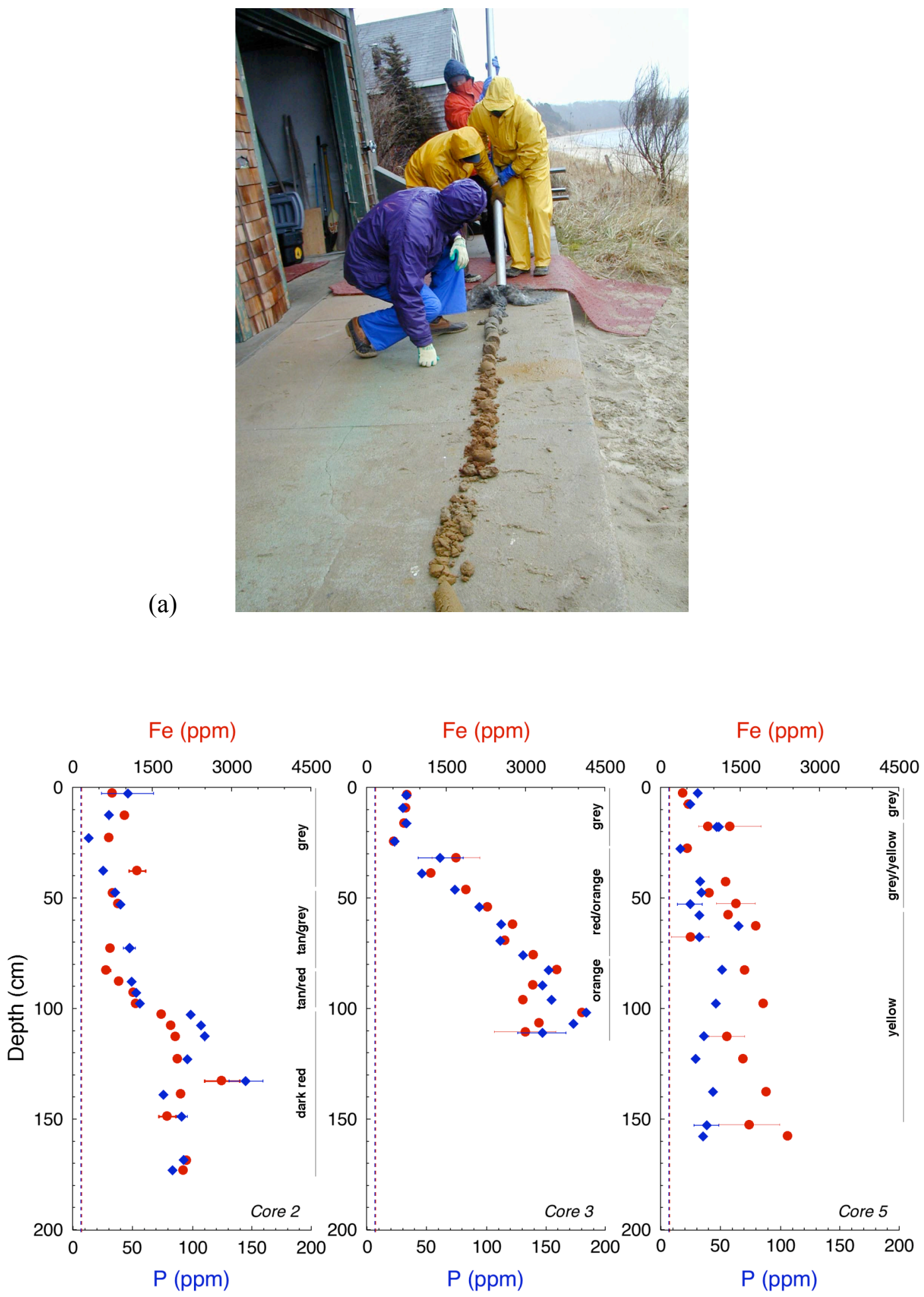

(b) 
Figure 8. (a) Scientists extruding a sediment core with taken through the subterranean estuary of Waquoit Bay, MA. Note the presence of iron oxides within the sediments at the bottom of the core (foreground). (b) Changes in iron and phosphate concentration with depth in three sediment cores similar to the one shown in (a). The open circles indicate Fe concentration (ppm: $\mu \mathrm{g} \mathrm{Fe} / \mathrm{g}$ dry sediment) while the solid diamonds represent $\mathrm{P}$ (ppm: $\mu \mathrm{g} \mathrm{P} / \mathrm{g}$ dry sediment). Error bars indicate the standard deviation for triplicate leaches performed on a selected number of samples. The dashed lines represent the concentration of Fe and $\mathrm{P}$ in 'off-site' quartz sand. Also shown is the approximate color stratigraphy for each core. The $\mathrm{R}^{2}$ value for Fe vs. $\mathrm{P}$ in cores 2,3 , and 5 is $0.80,0.91$, and 0.16 , respectively.

\section{Summary}

Groundwater discharge to the coastal ocean can be an important source of fresh water and dissolved solutes. Although a significant amount of research into the role of SGD in solute budgets has only occurred in the past decade or so, there is increasing evidence that solute loading from groundwater can be significant enough to affect solute budgets and even ecosystem health. Proper estimation of solute loads from groundwater requires confidant estimates of both the groundwater discharge rate and average solute concentrations in the discharging fluid, neither of which are easily determined.

Estimating groundwater discharge rates is complicated by the spatial and temporal variability of groundwater flow. A multitude of time-varying driving mechanisms complicate analysis, as does geologic heterogeneity. Nonetheless, a suite of tools from hydrogeology, geophysics, and geochemistry have been developed for sampling and measuring SGD.

The nature of geochemical reactions within near shore sediments is not well understood, yet recent studies have shown that important transformations occur over small spatial scales. This is an exciting and critically important area of research that will reveal important process in the near future. 


\section{References}

Bugna, G.C., Chanton, J.P., Cable, J.E., Burnett, W.C., Cable, P.H. 1996. The importance of groundwater discharge to the methane budgets of nearshore and continental shelf waters of the northeastern Gulf of Mexico. Geochimica et Cosmochimica Acta, 60: 4735-4746.

Burnett, W.C., Bokuniewicz, H., Huettel, M., Moore, W.S., Taniguchi, M. 2003. Groundwater and pore water inputs to the coastal zone. Biogeochem., 66: 3-33.

Burnett, W.C., P.K. Aggarwal, H. Bokuniewicz, J.E. Cable, M.A. Charette, E. Kontar, S. Krupa, K.M. Kulkarni, A. Loveless, W.S. Moore, J.A. Oberdorfer, J. Oliveira, N. Ozyurt, P. Povinec, A.M.G. Privitera, R. Rajar, R.T. Ramessur, J. Scholten, T. Stieglitz, M. Taniguchi, and J.V. Turner. 2006. Quantifying submarine groundwater discharge in the coastal zone via multiple methods. Science of the Total Environment, 367: 498-543.

Cable, J. E., W. C. Burnett, J. P. Chanton, and G. L. Weatherly. 1996. Estimating groundwater discharge into the northeastern Gulf of Mexico using radon-222. Earth and Planetary Science Letters, 144: 591-604.

Chanton, J. P., W. C. Burnett, H. Dulaiova, D. R. Corbett, and M. Taniguchi. 2003. Seepage rate variability in Florida Bay driven by Atlantic tidal height. Biogeochemistry, 66: 187-202.

Charette, M. A., Buesseler, K. O., Andrews, J. E. 2001. Utility of radium isotopes for evaluating the input and transport of groundwater-derived nitrogen to a Cape Cod estuary. Limnology and Oceanography, 46: 465-470.

Charette, M. A., and E. R. Sholkovitz. 2002. Oxidative precipitation of groundwater-derived ferrous iron in the subterranean estuary of a coastal bay. Geophysical Research Letters, 29.

---. 2006. Trace element cycling in a subterranean estuary: Part 2. Geochemistry of the pore water. Geochimica Et Cosmochimica Acta, 70: 811-826.

Heath, R. C. 1998. Basic ground-water hydrology. U.S. Geological Survey Water-Supply Paper 2220.

Kim, G., Lee, K.K., Park, K.S., Hwang, D.W., Yang, H.S, 2003. Large submarine groundwater discharge (SGD) from a volcanic island. Geophysical Research Letters, 30(21), art. no.2098.

Kohout, F. 1960. Cyclic Flow of Salt Water in the Biscayne Aquifer of Southeastern Florida. Journal of Geophysical Research 65: 2133-2141.

Krest, J.M., Moore, W.S., Gardner, L.R., Morris, J.T. 2000. Marsh nutrient export supplied by groundwater discharge: Evidence from radium measurements. Global Biogeochem. Cyc., 14: $167-176$. 
Lee, D. R. 1977. A device for measuring seepage in lakes and estuaries. Limnol. Oceanogr., 22: 140-147.

Li, L., Barry, D.A., Stagnitti, F., Parlange, J.-Y. 1999. Submarine groundwater discharge and associated chemical input to a coastal sea. Water Resources Research, 35: 3253-3259.

Li, H.L., Jiao, J.J. 2003. Tide-induced seawater-groundwater circulation in a multi-layered coastal leaky aquifer system. Journal of Hydrology, 274: 211-224.

Michael, H.A., A.E. Mulligan, and C.F. Harvey. 2005. Seasonal water exchange between aquifers and the coastal ocean, Nature, doi:10.1038/nature03935, 436: p.1145-1148.

Miller, D. C., and W. J. Ullman, 2004. Ecological consequences of ground water discharge to Delaware Bay, United States. Ground Water, 42: 959-970.

Moore, W. S. 1996. Large groundwater inputs to coastal waters revealed by Ra-226 enrichments. Nature, 380: 612-614.

---. 1999. The subterranean estuary: a reaction zone of ground water and sea water. Marine Chemistry, 65: 111-125.

Mulligan, A.E., and M.A. Charette. 2006. Intercomparison of submarine ground water discharge estimates from a sandy unconfined aquifer. Journal of Hydrology, 327: 411-425.

Paulsen, R. J., C. F. Smith, D. O'Rourke, and T. Wong. 2001. Development and evaluation of an ultrasonic ground water seepage meter. Ground Water, 39: 904-911.

Portnoy, J. W., B. L. Nowicki, C. T. Roman, and D. W. Urish. 1998, The discharge of nitratecontaminated groundwater from developed shoreline to marsh-fringed estuary, Water Resources Research, 34: 3095-3104.

Shinn, E.A., Reich, C.D., Hickey, T.D. 2002. Seepage meters and Bernoulli's revenge. Estuaries, 25: $126-132$.

Sholkovitz, E. R., C. Herbold, and M. A. Charette. 2003. An automated dye-dilution based seepage meter for the time-series measurement of submarine groundwater discharge. Limnology and Oceanography: Methods, 1: 17-29.

Slomp, C.P., Van Cappellen, P. 2004. Nutrient inputs to the coastal ocean through submarine groundwater discharge: controls and potential impact. Journal of Hydrology, 295: 64-86.

Talbot, J. M., K.D. Kroeger, A. Rago, M.C. Allen, and M.A. Charette. (2003) Nitrogen flux and speciation through the subterranean estuary of Waquoit Bay, Massachusetts. Biological Bulletin, 205: 244-245. 
Taniguchi, M., Burnett, W.C., Cable, J.E., Turner, J.V. 2002. Investigation of submarine groundwater discharge. Hydrological Processes, 16: 2115-2129.

Taniguchi, M., and Y. Fukuo. 1993. Continuous measurements of ground-water seepage using an automatic seepage meter. Ground Water, 31: 675-679.

Taniguchi, M., and H. Iwakawa. 2001. Measurements of submarine groundwater discharge rates by a continuous heat-type automated seepage meter in Osaka Bay, Japan. Journal of Groundwater Hydrology, 43: 271-277.

Valiela, I., Foreman, K., LaMontagne, M., Hersh, D., Costa, J., Peckol, P., DeMeo-Andreson, B., D’Avanzo, C., Babione, M., Sham, C.-H., Brawley, J., Lajtha, K. 1992. Couplings of watersheds and coastal waters: Sources and consequences of nutrient enrichment in Waquoit Bay, Massachusetts. Estuaries, 15: 443-457.

Webster, I. T., G.J. Hitchcock, and A.S Murray. 1995. Modelling the effect of salinity on radium desorption from sediments. Geochim. Cosmochim. Acta, 59: 2469-2476. 